\title{
HALF-WAY THROUGH THE BETTER REGULATION STRATEGY OF THE JUNCKER COMMISSION: WHAT DOES THE EVIDENCE SAY?
}

Claudio M Radaelli

Professor of Public Policy, University College London

Current Address: C.Radaelli@ucl.ac.uk

Accepted for Publication in

Journal of Common Market Studies

https://onlinelibrary.wiley.com/doi/abs/10.1111/jcms.12768

First published: 22 July 2018

\begin{abstract}
In 2015 the European Commission re-launched better regulation with a comprehensive strategy comprising principles of regulatory management, tools, methodological guidance, and oversight. Half-way through the legislature, we appraise the strategy and show how policy and politics intersect. Better regulation raises issues about inter-institutional relations because it is a fundamental exercise in controlling who does what in the law-making process of the European Union. Consequently, we report on how the European Parliament and the Council have responded to the Commission's strategy. We conclude by taking stock of what has been learned in the period 2015-2017 and point to the regulatory reform issues that will most likely dominate the agenda of the new Commission.
\end{abstract}

\section{Acknowledgements}

Research for this article was funded by the European Research Council, advanced grant Protego Procedural Tools for Effective Governance 694632. I wish to thank Thibaud Deruelle for research assistance and Claire Dunlop for having read the first draft. Lorna Schrefler kindly provided detailed comments on an early draft. Many thanks to Theofanis Exadaktlylos for his substantial and editorial suggestions. 


\section{HALF-WAY THROUGH THE BETTER REGULATION STRATEGY OF THE JUNCKER COMMISSION: WHAT DOES THE EVIDENCE SAY?}

Claudio M Radaelli

Journal of Common Market Studies 2018

\section{Setting the scene}

Better regulation - as identified in the discourse of the European Union (EU), is a set of activities and evidence-based policy instruments. Its aims are to appraisal new policies (regulatory or not), to carry out systematic consultation, to undertake evaluations of regulations and domains of the acquis, and to generate regulatory management.

Better regulation has its own distinctive processes, actors, problems, inter-institutional agreements, and instruments, e.g., impact assessment, legislative evaluation, and consultation. Consequently, we can call it a public policy. The difference with other policies like health and safety or environmental protection policy is that better regulation is supposed to be systematic in its goals and activities, no matter what policy sector is considered. It is horizontal so to speak - international organizations call this the "whole of government approach' to regulatory quality (OECD, 2015).

Of course, the fact that this policy is called by the EU institutions and others 'better regulation' does not necessarily mean that it delivers on high quality regulation, or that the very notion of regulatory quality is accepted by every player. Objectively, the EU better regulation policy is one possible incarnation of some ideas about regulatory reform and the governance of EU legislation. With this caveat, we can carry on with the terminology adopted in the official documents of the EU, which, after some oscillations in past between 
'smart' and 'better' regulation (European Commission, 2010; European Commission, 2015a), seem now to have settled on 'better'.

\section{Better regulation: Policy and Politics}

To grasp the fundamentals of the year in review, it is useful to go back to 2015 when the First Vice-President of the Commission Frans Timmermans defined his strategy for this policy domain (European Commission, 2015a). Of course, there are other prominent actors, including the European Parliament, the Council of the European Union, the member states, the business community and non-governmental organizations - we will consider some of them in due course. But at the very least the Commission has the advantage of moving first when it comes to defining the agenda.

The early attempts in this field dated back to the 1990s, with a more consistent effort to align objectives and instruments since 2002. In May 2015, the Commission defined the scope of better regulation for the Juncker Commission. The highlights of the Communication by Timmermans (European Commission, 2015a) and accompanying documents were: the objective of closing the policy cycle by putting ex-post evaluation at the beginning of any work on new proposals (the so-called 'evaluate first' principle, European Commission, 2010); an enhanced flow of consultations involving stakeholders at different stages of the policy cycle; a re-defined body for the scrutiny of better regulation activities (the Regulatory Scrutiny Board); a single set of methodological templates for better regulation activities (a toolbox running above 400 pages, re-adjusted in summer 2017 to take into account the experience of the first two years). In a sense, this is the technical/instrumental level, 
enshrined in, or accompanied by, a political setting - if you wish, you can call the former policy and the latter politics.

On the policy dimension, three observations are necessary. First, ex-post regulatory and legislative evaluation is a complex activity where most of the OECD countries have just raised awareness (OECD, 2014). By taking the decision to embark on both systematic expost evaluation and making evaluation the first step in the planning of new legislation, the Commission set a very high bar. Second, massive doses of consultation across the board, new platforms for stakeholders, fitness checks were consultation is the main method to appraise regulatory burdens and compliance costs mean that the Commission, in the period considered, has been seeking legitimacy from the input given by stakeholders. Whether this is for the Commission more important than legitimacy provided by accurate economic analysis and reputation for independence we cannot tell.

Third, the Regulatory Scrutiny Board (RSB) emerged since 2015 as more than just a watchdog. Although the Commission had the experience of the Impact Assessment Board since 2007 (a body staffed part-time by Commission's high level officials from selected Directorates General), the RSB is chaired by a Commission's director general and consists of three independent experts recruited from outside the EU institutions and three high-level Commission officials. All RSB members work full-time, are bound to the principle of collective responsibility - this has generated a common intent and esprit de corps - and have a mandate that is wider than that of the old Impact Assessment Board. The RSB in fact evaluates the quality of impact assessments of new legislation, major ex-post regulatory evaluations and fitness checks of existing legislation, can intervene on implementing and delegated acts, as well as being able to offer advice on methods and issues that cut across 
different types of assessment. Behind the emergence of the RSB lies a tension between some member states (led by Germany, the Netherlands and the UK in this case) who wanted a totally independent regulatory oversight body, and the Commission, close to the idea of keeping oversight within the perimeter of its treaty-defined right to initiate legislation.

With this observation, we have already entered the politics dimension. Scratch beneath decisions on the scope, mission and membership of the RSB and you will discover fundamental questions about who is and should be in control of the life-cycle of policy. Arguably, member states would trust more a regulatory oversight body with no Commission's officials. For the Commission, instead, opinions on the quality of impact assessments of proposed initiatives should remain a component of the internal process of monitoring and learning - that is, the policy conversation among the Secretariat General, the Directorates General, and the Commissioners.

The second feature of the politics dimension is the bold statement made by the Commission that all the activities of the annual work programme are informed, appraised and supported by better regulation. Take the work programme for 2016: here we read that all initiatives for the Digital Single Market, the Energy Union, Security, Migration, the Capital Markets Union, the Action Plan for Fair and Efficient Corporate Taxation, the Single Market Strategy for goods and services “are underpinned by the Commission's new Better Regulation Agenda" (European Commission, 2015b: 2). Similarly, in the work programme for 2018 we learn that: "Today, more than ever, there is a need for sound preparations, evaluations and evidencebased policy-making. Any decision, any proposal must take into account all available facts and evidence in a structured and comprehensive way. The stakes are too high, the challenges too complex to take any other approach. This is why Better Regulation underpins 
all the Commission's work and continues to ensure that our proposals are based on the best available information" (European Commission 2017c: 13). This implies that the Commission is prepared to be judged on the quality and usage of the evidence-based instruments deployed in all these areas.

At the same time (this is the third politics-relevant annotation), the Commission since 2015 has made it clear that it is no longer prepared to take the blame for the inefficiency and poor quality of regulatory outcomes. On the one hand, it accepts the high bar of evidencebased standards for its own activities. On the other, responsibilities should be separate. It should be clear to the public if and when the European Parliament or the Council impose amendments that generate new administrative obligations and higher compliance costs, or when member states customize legislation by introducing new regulatory costs.

For this reason, the Commission put on the table a new inter-governmental agreement on better regulation - to bind the Council and the Parliament to evidence-based appraisals of their major amendments. It has also insisted that member states should report on their additional (that is, beyond EU regulatory floors) regulatory obligations. A 2003 interinstitutional agreement on these matters was never properly implemented. The new agreement was negotiated and eventually agreed in 2016 with the name inter-institutional agreement on better law-making (OJ L 123 vol.59, 12 May 2016). The reference to lawmaking instead of regulation is a good sign, because it goes beyond better regulation to capture in principle all law-making activities where the three main institutions of the EU need to cooperate on evidence-based policy. The change of label hopefully means more involvement of the EU legislator - up until now better regulation has been perceived as a 
policy of the Commission, whilst there is no doubt that law-making points towards all institutions involved in making legislation.

The fourth politics element is tricky. It is about the relationship between better regulation and subsidiarity. In the period 2015-2017, the Commission has taken a number of decisions grounded in Juncker and Timmermans's beliefs about the legitimate scope of subsidiarity and the notion that the Commission should be, as they often put it, big on big things and small on small things (see for example, Jean-Claude Juncker: The Juncker Commission: The Right Team to Deliver Change, Brussels, 10 September 2014; http://europa.eu/rapid/pressrelease SPEECH-14-585 en.htm). To illustrate, in 2015 the Commission withdrew 73 proposals - not because they did not pass an impact assessment or there was no sufficient evaluation of the existing legislation, but because they were not considered acceptable given the approach of the Juncker Commission to subsidiarity or, in other cases, did not have realistic changes to go through the legislative procedure. Although this has created political controversy and a Court's decision on the scope of the power to withdraw (Case C409/13), the withdrawal of proposals, in general, is not underpinned by the usage of evidence-based instruments. Rather, it is an indicator of a regulatory philosophy of a political Commission like the present one.

\section{The main achievements of the Commission}

Two years after the 2015 Communication, we can appraise some preliminary results of the better regulation strategy. The Commission published a mid-term review of the better regulation agenda (European Commission, 2017a). The European Court of Auditors published its performance audit on the EU system of ex-post review of legislation (check REF 
at proofs stage). Thus, it is an appropriate time for social scientists too to review the evidence available.

The main achievements of the Commission are the strong emphasis on consultation, the attempts made to include ex-post legislative evaluation into the policy cycle, the de facto independence of the RSB and its capacity to handle different types of scrutiny. On the minus side of the equation, there are questions about domains where impact assessment is not carried out or not done properly (e.g. the governance architecture of the Eurozone); whether impact assessment really informs the development of the proposals of the Commission (note that the final impact assessment and the proposal are published simultaneously); the methodological robustness and timing of the ex-post evaluations; and the fact that, considering the amount of work done, the RSB members are not adequately supported by a team of economists and social scientists.

Let us start with the core of regulatory oversight, the RSB, whose independence is also crucial for the legitimacy of the overall better regulation agenda. On impact assessment, the RSB provides an opinion. It can approve or ask the relevant Directorate General to review and re-submit the report. By late 2016, the RSB started to publish a third type of opinion: 'positive with reservations'.

In 2017, the RSB scrutinized 53 impact assessments. 7 evaluations were examined by the RSB in 2016, with a jump to 17 in 2017. The RSB focuses on the staff working document (SWD) in which the Commission reflects on the evaluation. This SWD is the document where the service of the Commission signals its ownership of the evaluation carried out by the consultants and other activities (e.g. a stakeholders conferences) that inform the learningfrom-the-results process. 
How does the RSB go about its scrutiny function? In 2017 the first opinion on impact assessment was negative in 23 cases, positive in other 12 and positive with reservations in the remaining 18 cases. As for second opinions on impact assessments that were found below standards at the first stage of review, 1 was negative, 12 positive with reservations and 4 were never resubmitted after the first negative opinion (RSB 2018: 12). There was much discussion as to whether the Commission should still carry on with proposals with two negative RSB opinions. The answer is that the RSB does not say YES or NO to a proposal: a double-negative means that the proposal does not meet the RSB standards for evidencebased policy. But there may be political reasons that make the Commission carry on. The presence of a published motivated double negative opinion adds transparency and flags up issues that should be taken into account in the legislative procedure.

The revision of the 2015 Toolbox in summer 2017 clarifies and provide guidance on the approach to evaluation of the Commission, e.g. the notion of evaluate first and back-to-back evaluations and impact assessments (European Commission, 2017d). As mentioned, the idea is that impact assessment work should draw on ex-post evaluations. A couple of studies deal with the results achieved in closing the policy cycle (Mastenbroek et al., 2016; van Golen and van Voorst, 2016). Van Golen and van Voorst gathered 309 ex-post legislative evaluations and 225 impact assessments. They found that only 9 ex-post evaluations use impact assessment and 33 impact assessments draw in some ways on ex-post evaluations. Their data do not cover the last two years, though. In 2016/2017 some evaluations were published at the same time as the impact assessment and legislative proposal.

One problem is what kind of report or study meets the threshold to be called an evaluation and how close to the impact assessment is its publication date? It is very difficult to plan 
evaluations so that they are temporally aligned with the impact assessment and the work on new proposals. In some cases, the Commission's impact assessment reports on the presence of 'studies'. Does a study or report equal to evaluation? The RSB report for 2017 observes that in that year 30 out of 40 impact assessments aiming to revise legislation were supported by an evaluation (this is a 75\% rate). Interestingly, for the RSB 10 of these evaluations were inadequate, 6 not properly used, and the other 14 are cases of 'good use of evaluation' (RSB 2018: 23). Mastenbroek and colleagues (2016) have designed a scorecard to appraise the quality of legislative evaluations carried out by the Commission. The evaluations in their sample do not fare well on 'justification of methods' (only $15 \%$ of the sample) and 'reliability' (29\%).

If evaluation ought to connect back-to-back with impact assessment, the classic evaluations of cohesion policies offer little assistance to design policy (Dunlop and Radaelli, 2017 for details). This explains why the Commission needs to draw on legislative evaluations and new evidence-based instruments like REFIT, fitness checks and Cumulative Cost Assessments. A fitness check is conceptually the same as the evaluation of an individual intervention but it covers a range of rules that have a common regulatory goals or share some objectives and for this reason have to be examined together (European Commission, 2017d). REFIT (Regulatory Fitness and Performance) belongs to the attempt to review the entire acquis with a strong emphasis on the involvement of stakeholders. At its core, it is a simplification and burdens reduction initiative - the official slogan is "identify opportunities for simplification and reducing unnecessary costs every time the Commission proposes to revise existing law" (European Commission 2017e: 4). It is now incorporated in the annual Commission work programme as quality review of existing EU legislation. Indeed, REFIT is 
designed as a rolling programme and as such identifies where to withdraw proposals - here we see a connection between better regulation and the approach to subsidiarity.

The 2018 work programme includes 17 legislatives initiatives under REFIT, 15 withdrawals and 3 repeals. The programme adds 12 new REFIT simplification initiatives in the priority areas of the Juncker Commission, e.g., looking at reporting requirements in the sectors of environment, the fisheries control system, consumer law, trans-European transport networks, ID cards and emergency travel documents.

The methodological foundations of REFIT remain shaky. Exactly because of its conceptual ambiguity on the policy dimension (not a proper evaluation tool since some REFIT exercises are just appraisals of some regulatory costs) REFIT has been a political springboard for a variety of actions: consulting stakeholders, preparing hit lists of regulations to be targeted, reducing administrative burdens and compliance costs for business, slowing down regulatory action in some sectors, and withdrawal of proposals.

Since 2015 the Commission has experienced with platforms to collect comments on irritating or burdensome regulations, following the example of similar platforms in the UK and Belgium. REFIT indeed has a two-tier platform for dialogue with stakeholders and member states. Essentially the platform consists of two standing groups, one for governments and one for stakeholders. Since its creation, the REFIT platform has adopted 58opinions based on more than 280 public suggestions to make EU laws more efficient (European Commission, 2017e). Oddly enough, the REFIT platforms are chaired by Anne Bucher, the head of the Regulatory Scrutiny Board, who deputizes Timmermans on this exercise. There is no conceptual connection between the RSB scrutiny activity and the REFIT platforms. 
Since 2013, a tool called 'cumulative cost assessment' appeared under the REFIT umbrella. The cumulative cost assessment is not an evaluation. It performs a different function. It considers a single sector and attempts to measure the effects of different EU rules on a sample of representative facilities. The early applications of the cumulative cost tool were in the automotive, steel and aluminum sectors (Schrefler et al., 2015).

\section{The European Parliament and the Council}

Let us turn to the other EU institutions. The European Parliament has invested in capacity building by increasing the number of members of staff with the skills necessary to exercise oversight of the Commission's impact assessments and evaluations and to brief the parliamentary committees. Looking at the detailed, meticulous work of the European Parliament Research Service (EPRS, especially directorate C, Impact assessment and European Added Value) at various stages, from inception appraisals to the final impact assessments of the Commission, one has the impression that there is some duplication of work done by the RSB. But, here is the counter-argument, the EPRS is an internal EP voice, as opposed to the external voice of the Commission - this internal voice is heard by the committees, thus raising attention and amplifying some of the RSB messages. Further, the MEPs may be interested in impacts and dimensions that for the RSB are not priorities hence EPRS complements what the RSB does.

Be that as it may, the European Parliament scrutiny of better regulation covers also the expost dimension. Already in December 2015, two EPRS researchers (Schrefler and Huber, 2015) provided the Members of the European Parliament with a rolling check-list of all evaluations under way at the Commission (this includes both expenditure programmes and 
ex post legislative evaluations). They found that at that time there were 525 planned and on-going evaluations, of which 3\% originated by the Commission's work program, specifically the commitment to 'evaluate first'.

The variety of information on these evaluations is indeed puzzling, making it difficult for the European Parliament to even just keep track of it. In November 2017, Schrefler found 507 planned and on-going evaluations. She concluded that "Until recently, the overall picture of Commission evaluations remained complex and difficult to reconstruct for external actors. Progress towards the full implementation of the 2015 Better Regulation Guidelines has now clarified the status of on-going and planned Commission evaluations considerably. Conversely, accessing completed evaluations, namely Commission evaluation staff working documents and the underlying external studies, remains more challenging" (Schrefler, 2017:5; Timmermans was challenged by a Parliamentary question on this issue http://www.europarl.europa.eu/sides/getDoc.do?pubRef=-//EP//TEXT+WQ+E-2017$\underline{007614+0+D O C+X M L+V 0 / / E N \& l a n g u a g e=e n)}$.

Do Member of the European Parliament (MEPs) use evaluations? In the 220 ex-post legislative evaluations examined by Zwaan et al. (2016), no question (on evaluation) has been asked by an MEP to reflect on policy performance or how legislation has achieved its goals. Most of the variance in the MEPs questions is explained by the political muscle-flexing exercises pitching the Parliament versus the Commission. Our analysis of the questions for 2017-March 2018 shows 39 questions that either mention an evaluation published by the Commission, call for an evaluation or discuss ongoing evaluations. When it comes to reflecting on policy performance, 7 questions clearly reflect on policies that have been evaluated as underperforming, whereas by not meeting clear numerical standards, 
(question E-006722-17 on the tap water directive), imperfectly achieving the aim of said policy (question E-001017-18 on the legal instrument to achieve goals set in the "EU blood directive"), or in ways that do not warrant the conclusions drawn by the Commission (question 0-000034/2017 on the implementation of the Nature directives). 5 questions on on-going evaluations demand that the evaluation be geared towards dimensions of policy performance or ask the Commission to be more explicit on the evaluation strategy. In the recent period we examined, MEPs cast a critical eye on the evaluation process, e.g. by questioning the method of evaluation (17 questions), asking for actions to be taken once the evaluation is done (10 questions) or pointing towards lack of evaluation (17 questions). Sometimes the reference to policy performance is subtle or absent, as conclusions from an evaluation (sometimes under the form of a quote) will be taken as the rationale and/or introduction to the question, without clearly discussing policy performance (10 questions).

\begin{tabular}{|l|c|}
\hline Types of Parliamentary Questions on Evaluation January 2017-March 2018 & $\begin{array}{l}\text { Number of } \\
\text { questions }\end{array}$ \\
\hline $\begin{array}{l}\text { Reflecting on Policy performance: questions on policy performance following an evaluation, } \\
\text { or on the gap between performance and the MEP expectations about performance }\end{array}$ & 7 \\
\hline $\begin{array}{l}\text { Discussing ongoing evaluations (at the time of the question): questions on MEPs demand } \\
\text { for a preview of the evaluation, or firsthand information on either performance or impact }\end{array}$ & 5 \\
\hline $\begin{array}{l}\text { Questioning/suggesting methods of evaluation: Rationales, dimensions, issues the MEP } \\
\text { wants to see in an evaluation }\end{array}$ & 17 \\
\hline $\begin{array}{l}\text { What is the follow-up once the evaluation is published? MEPs showing interest in knowing } \\
\text { what the effect of an evaluation will be on the Commission's agenda or work programme }\end{array}$ & 10 \\
\hline $\begin{array}{l}\text { Lack of evaluation pointed out/ asking for an evaluation (explicitly or implicitly): More } \\
\text { evaluation is sometimes demanded explicitly, other times the request is phrased implicitly eg } \\
\text { "Will the Commission conduct an evaluation of ...." }\end{array}$ & 17 \\
\hline $\begin{array}{l}\text { An existing evaluation can be identified as the rationale to ask the question, without clear } \\
\text { reference to performance: Questions that are based on the conclusions of a specific } \\
\text { evaluation or that refer to a programme of evaluations }\end{array}$ & 10 \\
\hline
\end{tabular}


In principle, the inter-institutional agreement of 2016 binds together the Commission, the European Parliament and the Council. In particular, the agreement makes the statement that the impact assessments of the Commission should be presented in ways that facilitate the consideration by the Council and the European Parliament. The secretariat of the Council has elaborated a procedure so that the different formations should start their discussion with an examination of the underlying impact assessment, prior to getting into the details of proposed legislation.

The Council formations have responded with different degrees of commitment - arguably reflecting the silos mentality still prevalent. Definitively, there is motivation to take the better regulation agenda seriously in the Council formations that are closer to economic problems, such as the Competitiveness Council. The inter-institutional agreement also states that the Council and the European Parliament will carry out impact assessments of their substantial amendments to the Commission's proposals "when they consider this to be appropriate and necessary for the legislative process" (art.14). The secretariat of the Council, which is endemically under-staffed to produce impact assessments, launched a tender in autumn 2017 for a framework contract to support this analytical work.

In these inter-institutional relations, there are also political issues - like we said, policy and politics intersect. One is that the Council is notoriously hostile to raising awareness for goldplating and more generally the regulatory responsibility of member states in implementing and delivering legislation. The Council wants to keep the Commission accountable, not the member states. Another is that the inter-institutional agreement does not define the exact moment or threshold when the impact assessment of amendments should be carried out. It 
is up to the European Parliament and the Council to identify case-by-case the conditions under which this is appropriate and necessary - thus, there are no monetary thresholds above which an amendment generating additional regulatory costs should be looked at analytically.

Thirdly, both for the European Parliament and the Council, evidence-based activities stand in the way of more political discussions. They are so to speak grains of sand that can slow down or make it more difficult to talk 'politically', especially in trilogues - although in principle robust evidence should open the eyes of the negotiators and facilitate political work.

Fourthly, during the last two years the Competitive Council and the Commission have competed over the definition of what better regulation should be about. We have already seen the coordinates of the Commission's interpretation of problems and solutions. The Council agrees with the general coordinates, but on specific details it wants to see more emphasis on the reduction of administrative burdens. The political bone of contention is whether the EU should have regulatory targets similar to the UK's Business Impact Target (Department for Business, Energy \& Industrial Strategy, 2016; National Audit Office, 2016). On several occasions, for example in May 2016, the Competitiveness Council urged the Commission "to rapidly proceed on this to enable the introduction of regulatory targets in 2017" (Council of the European Union, 2016: 5). For the Commission, a business impact target is unfeasible and would skew the usage of evidence-based tools towards meeting the target rather than delivering net policy benefits. Noting the reluctance of the Commission, seven national regulatory bodies grouped under the RegWatchEurope banner commissioned a feasibility study on introducing EU-wide regulatory targets (Renda, 2017) - 
to push the Commission in this direction. The final episode (for now) in this tug-of-war was in October 2017, when the Commission stated that targets are neither feasible nor appropriate for the EU. The target "may lead to undue deregulation because 'necessary costs' to achieve regulatory benefits are not distinguished from 'unnecessary costs'. A burden-reduction policy of this sort will not have the necessary legitimacy among stakeholders" (European Commission, 2017b: 44).

\section{Conclusions}

This Commission is committed to the better regulation agenda. The bar has been set high, thus it is not surprising to observe the difficulty with the principles of evaluating first and closing the policy cycle. We do not have the counterfactual of how EU legislation would look like if impact assessments and the tools of better regulation did not exist. The causal link between better regulation and the quality of EU rules is a fascinating yet elusive object of study, especially if we extend regulatory quality to the dimension of how rules are delivered and experienced by firms and citizens in the member states (European Commission, 2017f). Even more daunting is the question about regulation and innovation - Commissioner Moedas has started the conversation (European Commission, 2016) but this important relationship will most likely mature in the next Commission.

Politically, there is tension between the de-regulatory vision of some Council formations and some member states (the UK being a classic champion) and the approach of the Commission, as shown by the controversy on the feasibility of an EU-wide business impact target. Perhaps with Brexit the Commission will find it easier to fight for its notion that the 
better regulation agenda should deliver net benefits rather than just reducing regulatory costs.

The connection between better regulation and subsidiarity remains a delicate issue. In launching the new industrial strategy on 13 September 2017, Juncker announced a new task force led by Timmermans on subsidiarity and proportionality (President Juncker's State of the Union address, http://europa.eu/rapid/press-release SPEECH-17-3165 en.htm). The task force was set up in November 2017 with members from national parliaments and the committee of the regions. It should clarify the principles of subsidiarity and proportionality and identify policy sectors that should be given back to EU countries or re-delegated to the EU.

Thinking of the next Commission, the key questions are more likely to be around subsidiarity and better regulation, regulation and innovation, the evolution of the RSB (totally independent or half-and-half?), the added value of the inter-institutional agreement, and whether Juncker and Timmermans will deliver a set of robust evaluations that will provide the baseline for the planning of future policies.

\section{References}

Council of the European Union (2016) Council Conclusions on 'Better Regulation to Strengthen Competitiveness', Brussels, COMPET 21 RECH 135, 8849/16, 18 May 2016.

Department for Business, Energy \& Industrial Strategy (2016) Business impact target: Statutory Guidance, London, November 2016. 
Dunlop, C.A. and C.M. Radaelli (2017) If evaluation is the solution, what is the problem?, in N.

Zahariadis and L. Buonanno (Eds) The Routledge Handbook of European Public Policy, London, Routledge, 331-343.

European Commission (2010) Smart regulation in the European Union, Brussels COM(2010) 543

Final, 8 October 2010.

European Commission (2015a) Better regulation for better results: An EU agenda, Brussels

COM(2015) 215 Final, 19 May 2015.

European Commission (2015b) No time for business as usual, Commission work programme 2016, Strasbourg, COM(2015) 610 Final, 27 October 2015.

European Commission (2016) Better regulations for innovation-driven investment at EU level.

Brussels, Commission staff working document. https://ec.europa.eu/research/innovationunion/pdf/innovrefit staff working document.pdf Accessed in March 2018.

European Commission (2017a) Completing the better regulation agenda: Better solutions for better results, Brussels, COM(2017) 651 Final, 24 October 2017.

European Commission (2017b) Overview of the Union's efforts to simplify and reduce regulatory burdens, Staff working paper, SWD(2017) 675 Final.

European Commission (2017c) An agenda for a more united, stronger and more democratic Europe, Commission work programme 2018, Brussels, COM(2017) 650 Final, 24 October 2017.

European Commission (2017d) Better regulation toolbox. https://ec.europa.eu/info/betterregulation-toolbox en Accessed March 2018.

European Commission (2017e) REFIT Scoreboard Summary, Brussels, 24 October 2017. https://ec.europa.eu/info/sites/info/files/regulatory-fitness-and-performance-programmerefit-scoreboard-summary en 6.pdf Accessed in March 2018.

European Commission (2017f) Business Perceptions of Regulation; Flash Eurobarometer 451. Brussels.

Mastenbroek, E., S. van Voorst and A. C. M. Meuwese (2016) "Closing the regulatory cycle? A meta evaluation of ex-post legislative evaluations by the European Commission." Journal of European Public Policy 23(9): 1329-1348.

National Audit Office (2016) The Business Impact Target: Cutting the cost of regulation. Report by the Comptroller and Auditor General, HC 236 session 2016-2017, 29 June 2016.

OECD (2015) Regulatory Policy Outlook, Paris, OECD Publications.

Regulatory Scrutiny Board (2018) Annual report 2017. Brussels, European Commission. https://ec.europa.eu/info/sites/info/files/rsb-report-2017 en.pdf Accessed in March 2018. 
Renda, A. (2017) Introducing EU reduction targets on regulatory costs: A feasibility study, Brussels, Ceps publications, https://www.ceps.eu/publications/introducing-eu-reduction-targetsregulatory-costs-feasibility-study Accessed March 2018.

Schrefler,L. G. Luchetta and F. Simonelli (2015) "A New Tool in the Box? The Cumulated Cost Assessment", European Journal of Risk Regulation 1/2015, pp. 68-78.

Schrefler, L. and S. Huber (2015) Evaluation in the European Commission: Rolling check list and state of play, Brussels, EPRS

http://www.europarl.europa.eu/thinktank/en/document.html?reference=EPRS STU(2015)5 58789 Accessed March 2018.

Schrefler, L. (2017) Evaluation in the European Commission: Rolling check-list and state of play, Brussels, EPRS

http://www.europarl.europa.eu/RegData/etudes/STUD/2017/611020/EPRS STU(2017)6110 20 EN.pdf Accessed March 2018.

Van Golen and S. van Voorst, S. (2016) "Towards a Regulatory Cycle? The Use of Evaluative Information in Impact Assessments and Ex-Post Evaluations in the European Union." European Journal of Risk and Regulation 7(2): 388-403.

Zwaan, P, S. van Voorst, and E. Mastenbroek (2016) "Ex-post legislative evaluation in the European Union: Questioning the usage of evaluations as instruments for accountability" International Review of Administrative Sciences, 82(4): 674-693. 